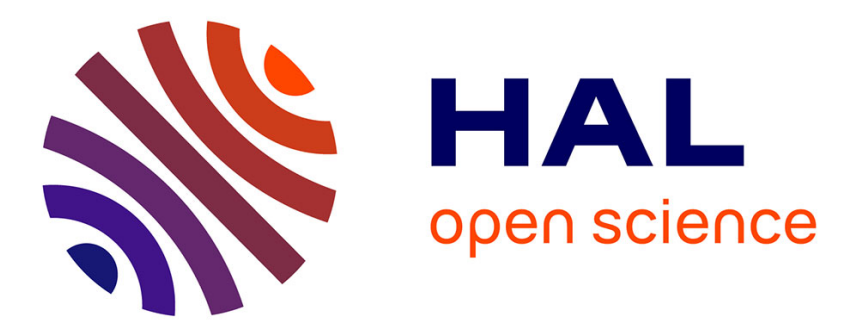

\title{
Time-place learning in the bee Melipona fasciculata (Apidae, Meliponini)
}

Thiago Jesus, Giorgio Venturieri, Felipe Contrera

\section{To cite this version:}

Thiago Jesus, Giorgio Venturieri, Felipe Contrera. Time-place learning in the bee Melipona fasciculata (Apidae, Meliponini). Apidologie, 2014, 45 (2), pp.257-265. 10.1007/s13592-013-0245-2 . hal-01234722

\section{HAL Id: hal-01234722 \\ https://hal.science/hal-01234722}

Submitted on 27 Nov 2015

HAL is a multi-disciplinary open access archive for the deposit and dissemination of scientific research documents, whether they are published or not. The documents may come from teaching and research institutions in France or abroad, or from public or private research centers.
L'archive ouverte pluridisciplinaire HAL, est destinée au dépôt et à la diffusion de documents scientifiques de niveau recherche, publiés ou non, émanant des établissements d'enseignement et de recherche français ou étrangers, des laboratoires publics ou privés. 


\title{
Time-place learning in the bee Melipona fasciculata (Apidae, Meliponini)
}

\author{
Thiago Nazareno Conceição Silva de Jesus ${ }^{1}$, Giorgio Cristino VenturIERI ${ }^{2}$, \\ Felipe Andrés León CONTRERA ${ }^{1}$
}

\footnotetext{
${ }^{1}$ Instituto de Ciências Biológicas, Laboratório de Biologia e Ecologia de Abelhas, Universidade Federal do Pará, Rua Augusto Corrêa, No. 1, Campus Básico, Guamá, CEP 66075-110, Belém, Pará, Brazil

${ }^{2}$ Laboratório de Botânica, Embrapa Amazônia Oriental, Trav. Dr. Enéas Pinheiro s/nº Caixa Postal, 48, CEP 66095-100, Belém, Pará, Brazil
}

Received 31 May 2013 - Revised 10 August 2013 - Accepted 20 September 2013

\begin{abstract}
Nectar and pollen are highly sought-after resources by different species of animals, including several stingless bees. Thus, learning the location of and time when a resource is available should be advantageous. This study investigated whether the stingless bee, Melipona fasciculata, exhibits food-anticipatory activity to maximize the exploitation of a renewable resource, an artificial food source with a restricted time schedule, which simulates an inflorescence. Our results showed that food-anticipatory activity occurs in this bee species, and foragers made periodic inspection visits before and after the feeder was available. These capabilities may have evolved to maximize the exploitation of profitable, short-lived food sources, as well as to minimize competition with other colonies and other animals. These differences are discussed and compared with different recruitment strategies and resource exploitation strategies in bees.
\end{abstract}

\section{stingless bees / resource gathering / food-anticipatory activity / spatiotemporal learning}

\section{INTRODUCTION}

Social Hymenoptera are notable in their ability to distinguish, to select, and to transmit spatial information to their nestmates to plan food collecting behavior (von Frisch 1993; Beugnon et al. 1996; Moore et al. 1998; Schueller and Jeanne 2012). Apis mellifera Linnaeus, 1758 , has been best studied with respect to circadian rhythms and is the model for studies on the insect "temporal memory" (or Zeitgedächtnis, Saunders et al. 2002). This memory allows honey bee foragers to make precise

Corresponding author: F.A.L. Contrera, felipe@ufpa.br

Manuscript editor: David Tarpy associations between the presence of food and time of the day, known as time-place learning (TPL; Schatzet al. 1999; Saunders et al. 2002; Thorpe and Wilkie 2006; Wagner et al. 2013). If the bees visit plant species that tend to offer nectar and pollen at specific times, or in the other hand, if the maximum rewards (nectar concentration or nectar volume), they offer are also restricted in time, such timeplace learning should be advantageous. Several studies established that $A$. mellifer foragers can be trained to collect food at virtually any time during the circadian cycle, and this ability of timing is controlled by an endogenous circadian clock (Moore et al. 1998; Moore 2001; Pahl et al. 2007).

Stingless bees (tribe Meliponini; Michener 2013) are eusocial bees that exhibit high flower fidelity (Slaa et al. 1998, 2003), are pollinators of 
many native plant species (Venturieri et al. 2012), and compete for food resources (intra- and interspecific competition). Some meliponine species are aggressive and can drive away other species from profitable food sources, while other species avoid direct conflicts and prefer to forage solitarily or have low recruitment rates (Johnson and Hubbell 1974; Hubbell and Johnson 1978; Nagamitsu and Inoue 1997; Jarau et al. 2003; Nieh et al. 2005; Lichtenberg et al. 2010). In a dynamic environment with changing resource availability and in the presence of competing species, knowing where and when to locate a resource is an important ability that may offer a significant advantage by allowing animals to optimize resource exploitation (Kronfeld-Schor and Dayan 2003; Thorpe and Wilkie 2006; Wagner et al. 2013).

Food-anticipatory activity in stingless bees has been described, but for relatively few species from the genus Trigona Jurine, 1807: in Trigona amalthea Olivier, 1789 (Breed et al. 2002), and Trigona fulviventris Guérin, 1844 (Murphy and Breed 2008). Besides this sparse information and some data on circadian clocks in stingless bees (e.g., Bellusci and Marques 2001; Oda et al 2007; Teixeira et al. 2011), little is known about time-memory in stingless bees and how it is related with the foraging activity of individuals and colonies.

We therefore studied stingless bee TPL through food anticipatory activity. We described the ability of foragers from Melipona fasciculata Smith, 1854 , to learn the location and the time of the day that a simulated inflorescence provided food. Our goal was to better understand the influence of time of the day on stingless bee forager behavior.

\section{MATERIAL AND METHODS}

\subsection{Site study and species}

We studied the Neotropical bee M. fasciculata, which is distributed in the Brazilian States of Maranhão, Mato Grosso, Pará, Piauí, and Tocantins (Camargo and Pedro 2012). Melipona fasciculata is a medium to large-sized species of meliponine, whose colonies are relatively small (about 300-400 bees; Kerr et al. 2001) and foragers normally forage solitarily, although they occasionally recruit to rich food sources (Contrera, unpublished).

The experiments were performed in the meliponary of the Botany Laboratory of Embrapa Amazônia Oriental, located in Belém, PA ( $1^{\circ} 26^{\prime} 08.44^{\prime \prime S}$ $\left.48^{\circ} 26^{\prime} 33.04^{\prime \prime} \mathrm{W}\right)$. The region has A $f$ climate, according to the updated climatic classification of Köppen-Geiger (Peel et al. 2007).

\subsection{Experimental protocol}

Workers of M. fasciculata were trained to visit an artificial feeder containing a 3:2 w/w syrup solution of sugar and water. Two drops $(5 \mu \mathrm{L})$ of rosewood essence were added per liter of syrup to increase the attraction of foragers, according to Nieh (2004). Each artificial feeder consisted of a set of $1.5 \mathrm{~mL}$ plastic tubes filled with syrup, radially arranged in a cylindrical container simulating an inflorescence (Figure 1). During the experiments, if any vial became empty due to bee's consumption, it was immediately refilled to prevent any bees from finding an unprofitable food source, which would affect the results.

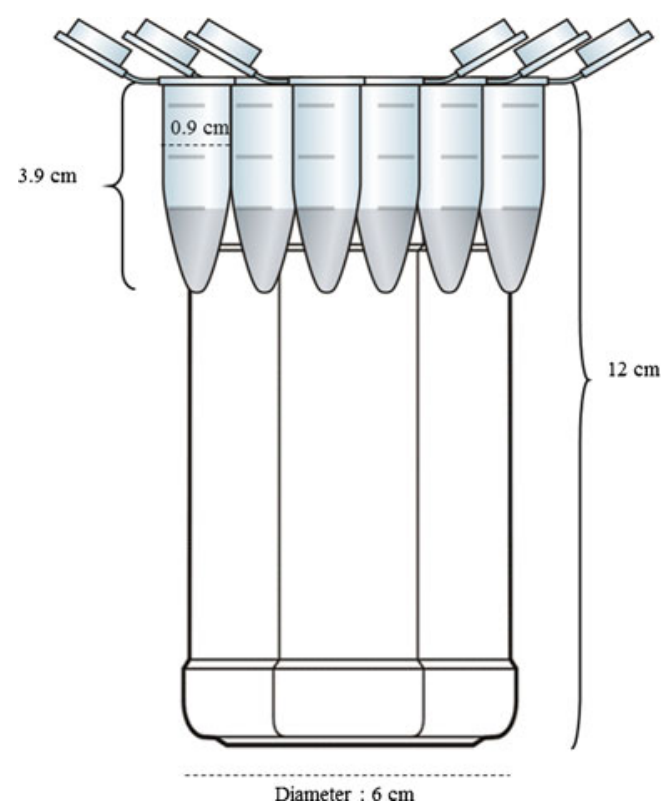

Figure 1. Design of the artificial feeder used for the training of M. fasciculata foragers, made of plastic tubes radially placed, simulating an inflorescence. 
To start the training, a single syrup-filled plastic tube was opened at $0800 \mathrm{~h}$ on the first day, near the entrance of the colony, so that foragers could be attracted to the syrup; these foragers were then labeled with one bright color of Acrilex ${ }^{\circledR}$ acrylic paint on their mesonotum (done without holding the bee and thus, not alarming her). At the moment they landed, the tube was gradually removed from the colony until the final position, at $200 \mathrm{~m}$ from the colony, where the entire set of plastic tubes was opened. Ten workers, which first learned the location of the "inflorescence" only at its final position, were used to evaluate the capacity of foragers of learning the time and place the food was offered. The process of moving the entire set of feeders up to the final position took at least $2 \mathrm{~h}$.

For individual identification of these ten bees, we used combinations of two colors to mark the mesonotum. While painting the bees, we recorded the time that each forager first arrived at the feeder. We define a "first forager" as a bee visiting our food source for the first time in its life. The bees that visited the feeder before it was set at the final position (200 m) were captured (and kept isolated in wooden hives) as soon as they visited the feeder in the final position. We did this to limit visitations at the start of the trial to only first foragers. The purpose of these captured bees was to recruit nestmates to the food source (through social enhancement or referential communication, review in Nieh 2004) to complete the ten foragers necessary for each trial. These captured foragers were not tested and were released at the end of the experimental days.

From the second to the fifth day (i.e., the first day the day of training), we observed, starting at $0500 \mathrm{~h}$ and ending at $1700 \mathrm{~h}$, those first foragers as well as recruits from the nest inspecting (or visiting) the feeder at its final position. From $0500 \mathrm{~h}$ to $0800 \mathrm{~h}$, the feeder array remained closed and did not offer any resources (syrup). From $0801 \mathrm{~h}$ to $1200 \mathrm{~h}$, the feeder array was provided syrup, simulating an inflorescence that provides nectar. From $1201 \mathrm{~h}$ to $1700 \mathrm{~h}$, the feeder array was again closed, simulating an inflorescence that has stopped offering resources. The feeder array was removed every day at $1700 \mathrm{~h}$ and replaced again at $0500 \mathrm{~h}$.

The number of recruits and the visitation schedule of every bee that visited the feeder were recorded throughout the course of the entire experiment. For the behavioral classification of foragers, we used the definitions from Biesmeijer and Vries (2001): A recruit was considered an "individual who uses external information to search for a previously unknown feeding resource," an inspector was an "individual not involved in feeding resource search, who spontaneously visits a previously known feeding source," and an employed forager was an "individual who knows and exploits a profitable feeding source, who does not use external information."

We used the following strategy to study anticipatory foraging and inspection behavior of the marked bees. We determined whether or not the foragers arrived at the feeder, in the following days of its discovery, at the same time they discovered it, or if the time of revisit significantly deviated from the discovery time. Inspection behavior was studied in relation to the time the feeder was offered in the days after training (from $0800 \mathrm{~h}$ to $1200 \mathrm{~h}$ ). Thus, the inspection could occur before the feeder was opened (from $0500 \mathrm{~h}$ to $0759 \mathrm{~h}$ ) or after the feeder was closed (from $1201 \mathrm{~h}$ to $1700 \mathrm{~h}$ ).

Four trials of this experiment were made during the rainy season (March-April) of 2011. We trained a maximum of ten workers per trial. Additional bees were recorded as recruits, captured as soon they landed on the feeder, and discarded to keep the maximum number of ten foragers visiting the feeder. We used a maximum number of ten foragers because M. fasciculata colonies are relatively small, with a small forager population (Contrera, unpublished data). In addition, they normally forage alone or in small groups. Thus, this number reflects a normal foraging group for this species and simplified the observation and labeling of individuals. For each trial, we used a different, new colony. In addition, in each trial, the final feeder position was at least $100 \mathrm{~m}$ away from the final feeder position used in other trials to avoid potential site bias. We used the criterion of anticipation of visitation, in relation to training schedules and time of feeder opening, to assess the TPL.

\subsection{Analysis}

The time of visitation, from the second to the fifth day, was compared with the time of the discovery of the resource to verify that the anticipation phenomenon 
occurs in M. fasciculata. The Watson-Williams' F-test was used to check the difference between the times of the first occurrence of the workers, comparing the first day, the time of discovery of the resource, and subsequent days (Zar 1999; Jammalamadaka and Sen Gupta 2001). We performed the same analyses on the last occurrence times of each day.

Cochran's Q-test was used to assess whether or not the bees visited (presence or absence) before (anticipation) and after (inspection) of the offering period of the resource in the feeder. We also made a circular-linear correlation to verify if there was a relation between time and recruitment rate (Zar 1999). Because the daily cycle of foraging is cyclical, these circular statics are more appropriate for testing our data than regular parametric statistics (Jammalamadaka and Sen Gupta 2001). For all tests, we considered a significance level of $5 \%$. For tests that involved multiple sampling of the same data (e.g., comparisons between visits on the first and second days and first and third days), we applied a sequential Bonferroni correction for multiple analysis (Zar 1999).

\section{RESULTS}

\subsection{Time-place learning}

On the training day, workers discovered the location of the feeder around $1100 \mathrm{~h}$, and in the following days, they revisited it before its opening time and the time they discovered it in the first day (around 0745 h, Figure 2). However, the first visits were more frequent before the opening time of the feeder $(87.5 \%$ of all first visits, from $0500 \mathrm{~h}$ to $0759 \mathrm{~h} ; n=112)$ than after this time $(n=16$; Cochran, $\left.Q_{(128,3)}=36.00, P<0.01\right)$.

All bees who visited the feeder displayed significant daily anticipation (Figure 2, WatsonWilliams, $\left.F_{(167,4)}=133.2, P<0.01\right)$. The variance decreased over days, and there was an increase in the average of visitation until the fourth day, with subsequent reduction on the fifth day, when the time of arrival became closer to the time of opening of the feeder (Figure 2). There was no significant difference between the third and fifth day $\left(F_{(68,1)}=2.397, P<0.126\right)$ and between the third and fourth days $\left(F_{(69,1)}=\right.$ $0.094, P<0.761)$, but there was between the fourth and fifth day $\left(F_{(65,1)}=549.8, P<0.022\right)$.
Regarding the time of the last inspection, there was a significant difference only between the first day and the other days $\left(F_{(167,4)}=6.393\right.$, $P<0.01$; Table I). The last visits were also more frequent before the closing time of the feeder than after it (Cochran, $\left.Q_{(124,3)}=20.45, P<0.01\right)$. Workers tended to converge their visits to the closing time of the feeder $(1200 \mathrm{~h})$, and even with the feeder closed, continued to inspect it regularly (Figure 3). Regular visits to the feeder occurred almost entirely during the opening hours of the feeder, between $0800 \mathrm{~h}$ and $1200 \mathrm{~h}$, corresponding to $97 \%(n=12,198)$ of all visits.

\subsection{Recruitment}

The recruitment was low (120 recruits at the final position of the feeder), with the highest number of recruits appearing during the first $3 \mathrm{~h}$ after the opening of the feeder (mean, $0929 \mathrm{~h}$, Figure 4). Nevertheless, the circular-linear correlation showed no direct relationship between the number of recruits and visitation time $(R=0.071, P=0.60)$.

\section{DISCUSSION}

Studies on time-place learning in stingless bees (Apidae, Meliponini) are scarce, comprising only investigations in T. amalthea (Breed et al. 2002) and T. fulviventris (Murphy and Breed 2008). Both studies demonstrated that the foraging workers exhibit TPL by anticipating the visitation to an artificial feeder days after its discovery. Obtaining more comparative data in other meliponine species will be helpful to understand interspecific variation in TPL and, in the future, to inform evolutionary and ecological analyses of this behavior.

The anticipatory behavior of $M$. fasciculata showed some similarities in relation to that of $T$. amalthea (Breed et al. 2002) and T. fulviventris (Murphy and Breed 2008). M. fasciculata showed anticipation of the time when food became available (at $0800 \mathrm{~h}$ in this experiment) and the time at which workers discovered the feeder on the first day (around $1100 \mathrm{~h}$ ). This indicates that workers of this species can learn 


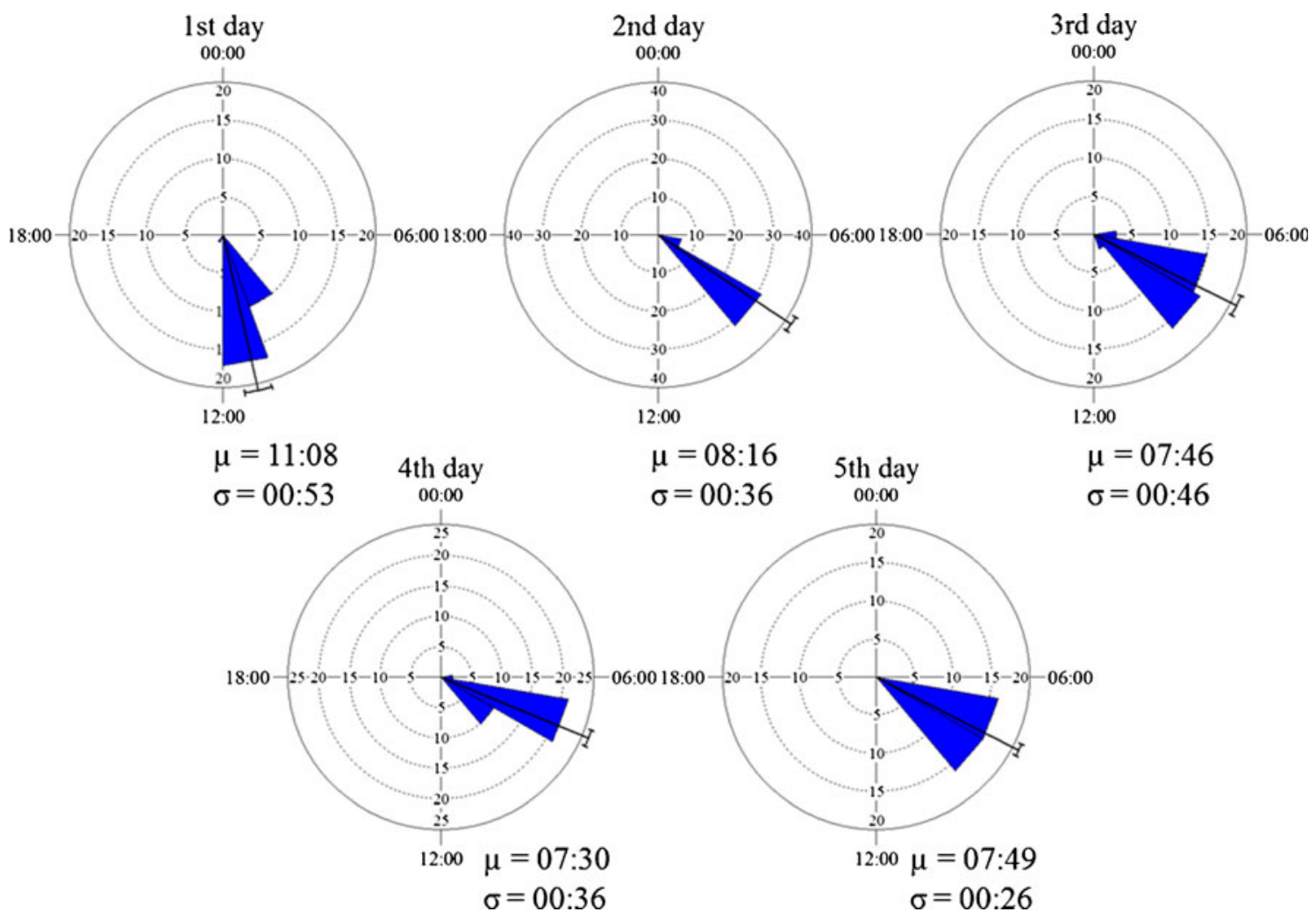

Figure 2. Time of arrival of M. fasciculata foragers to an artificial feeder on each experimental day (pooled data). The wedges indicate the number of visits in the corresponding time periods, the bar the mean time and the numbers in the concentric lines are a reference for the number of visits. In the first day, the foragers were trained to visit the feeder, starting at $0800 \mathrm{~h}$, and from the second to the fifth days, the feeder was set up in the final position at $0500 \mathrm{~h}$. At $0800 \mathrm{~h}$, it was opened and foragers could feed until $1200 \mathrm{~h}$, when it was closed. From $1200 \mathrm{~h}$ to $1700 \mathrm{~h}$, the feeder was closed, but inspections were still recorded. ( $\mu$ : mean of time of first occurrence; $\sigma$ : circular standard deviation of time).

the time of day at which a resource is discovered and also make periodic inspection visits before the resource is offered (from $0500 \mathrm{~h}$ to $0759 \mathrm{~h}$ ). Like A. mellifera, M. fasciculata developed an anticipatory feeding rhythm after only a single day of training (Moore 2001; Wagner et al. 2013).

A significant difference between the first day and the remaining days, in relation to the opening time of the feeder and time of resource discovery, can be attributed to the entrainment of the biological clock of the species (Zeitgeber) imposed by the feeder. After the discovery of the feeder, in ensuing days, many experienced foragers revisited the feeder before its opening time (Figure 2), most likely to increase the opportunity to monopolize the resource before any potential competitor could arrive. This implies a foraging strategy that maximizes resource collection and tries to minimize competition with species that arrive later or eventually find the resource (Hubbell and Johnson 1978).

The foragers that know the resource can inspect it and notify the other workers the condition of the feeder, although the decision of revisiting a feeder, in most cases, is individ- 
Table I. Comparisons (Watson-Williams' $F$-test) between the time of day of the last inspection of $M$. fasciculata foragers in an artificial food source.

\begin{tabular}{lll}
\hline Days & $F$ & $P$ value \\
\hline First and second & 8.288 & 0.006 \\
First and third & 7.389 & 0.009 \\
First and fourth & 15.445 & 0.001 \\
First and fifth & 14.88 & 0.001 \\
Second and third & 0.047 & 0.828 \\
Second and fourth & 2.571 & 0.113 \\
Second and fifth & 3.884 & 0.053 \\
Third and fourth & 1.19 & 0.279 \\
Third and fifth & 1.781 & 0.187 \\
Fourth and fifth & 0.329 & 0.569 \\
\hline
\end{tabular}

ual in Melipona Illiger, 1806 (Biesmeijer et al. 1998; Biesmeijer and Vries, 2001). Inspection (before or after the resource starts to be profitable) would allow the colony to re-use the resource quickly when it becomes profitable again (Antle and Silver 2009). TPL therefore allows meliponine bees to revisit the resource primarily by intrinsic mechanisms, rather than extrinsic information given by other workers. A similar pattern of bee TPL was recently described in $A$. mellifera, where foragers were differentiated in "persistent" and "reticent"; the persistent foragers were involved in inspection (reconnaissance) flights before the feeder was offering resources, and the reticent foragers only resumed visits in a

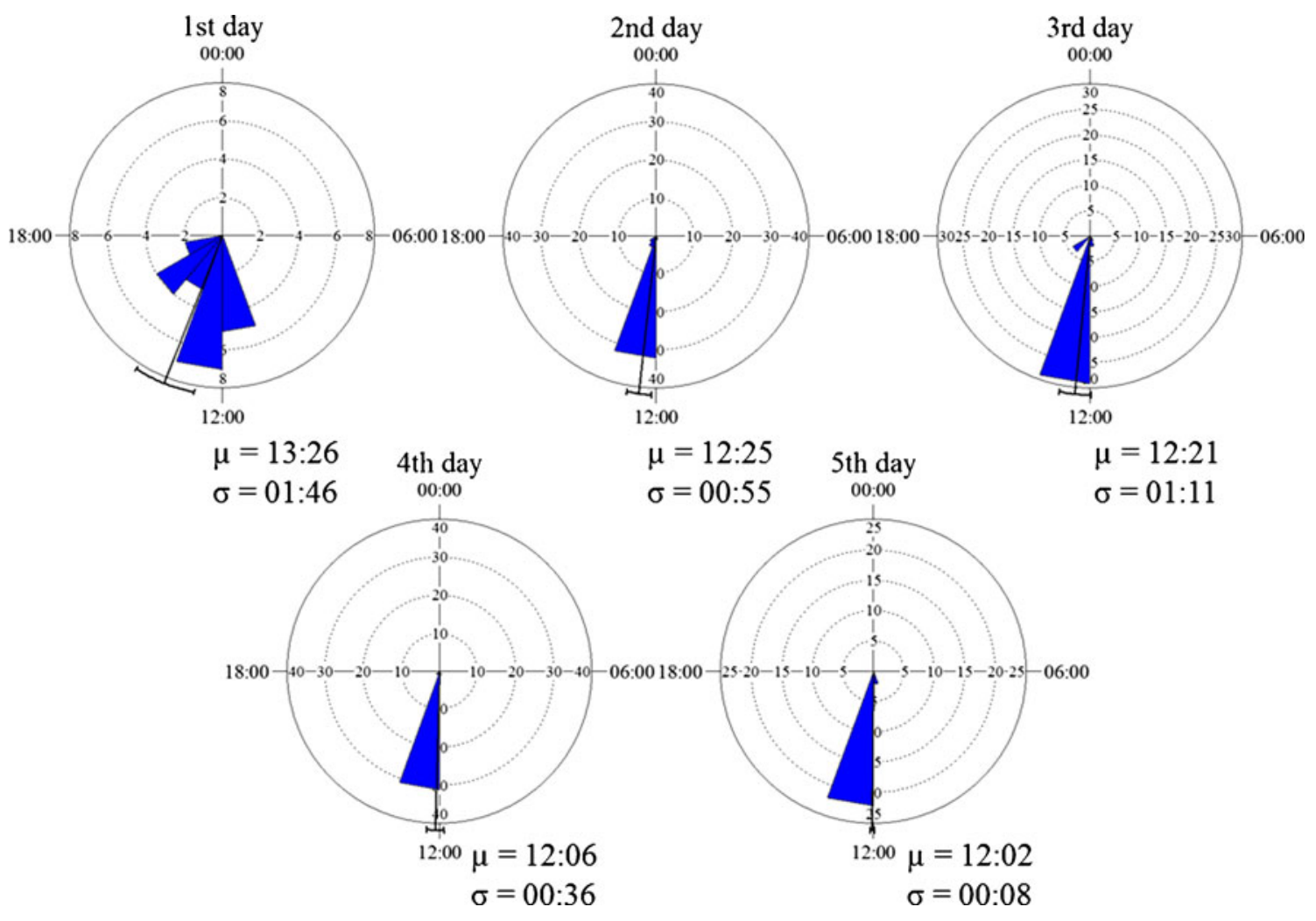

Figure 3. Time of the last visits of individual M. fasciculata foragers of to the artificial feeder in each experimental day (pooled data). The wedges indicate the number of visits in the correspondent time periods, the bar the mean time, and the numbers in the concentric lines are a reference for the number of visits. Timing of feeder set up and availability are identical to Figure 2 ( $\mu$ : mean of time of last occurrence; $\sigma$ : circular standard deviation of time). 


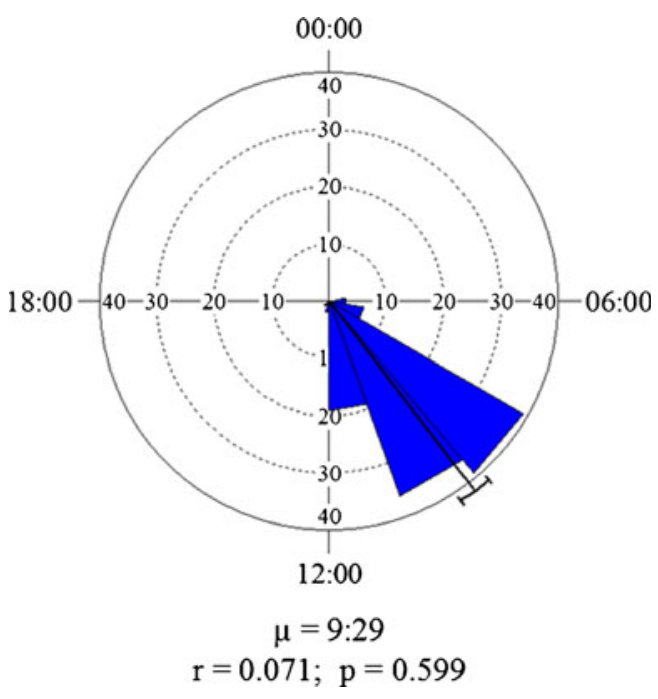

Figure 4. Time of the day when $M$. fasciculata recruits appeared in the feeder (pooled data) and results of the circular correlation test. The wedges indicate the number of visits in the correspondent time periods, the bar the mean time, and the numbers in the concentric lines are a reference for the number of visits $(\mu$ : mean of time of recruitment).

known food source after the visits of the persistent foragers (Moore et al. 2011; Wagner et al. 2013).

Time-place learning of a food resource should be evolutionarily favored when food is regularly available at a given place at constant intervals of time (Schatz et al. 1999). Floral resources, such as nectar and pollen, remain available in the environment at regular intervals in many cases (Edge et al. 2012). Therefore, it is presumed that animals depending on these resources present TPL, as demonstrated for $A$. mellifera (Moore 2001; Wagner et al. 2013; review in Antle and Silver 2009), T. amalthea (Breed et al. 2002), T. fulviventris (Murphy and Breed 2008), and M. fasciculata (this study). In this paper, anticipation by $M$. fasciculata employed foragers became evident through (1) the time of discovery of the resource (at approximately $1100 \mathrm{~h}$ on the first day), and (2) the opening time of the feeder $(0800 \mathrm{~h})$. A possible explanation behind this behavior is that, even when a given resource decreases, bees continue to visit and inspect it because less energy is spent revisiting an already known resource than in constantly searching for new, abundant resources. The same applies to inspection visits after the feeder was closed (from $1201 \mathrm{~h}$ to $1700 \mathrm{~h}$ ). Inspections may incur some cost for foragers but should be minimal if only a few experienced foragers are involved. Moreover, the benefits should be substantial if these experienced foragers can quickly reactivate colony mass foraging for the resource, beating out potential competition.

Differences in TPL may facilitate coexistence of different species. Even when species have similar optimal conditions, such as temperature, the timing of flight activity is not necessarily identical, thus allowing temporal partitioning of flower resources (Kronfeld-Schor and Dayan 2003). The highly accurate temporal memory exhibited by $M$. fasciculata in our study should allow this species to exploit the resource as quickly and efficiently as possible, allowing it to avoid direct competition with species that are more ecologically dominant and mass recruit. For example, foragers of species in the genus Trigona can expel species with fewer recruits from a valuable resource (Johnson and Hubbell 1974). Further studies comparing the accuracy in the TPL among different meliponine species and $A$. mellifera in standardized and natural food sources are necessary to understand the role of the bee's time and location memory (Saunders et al. 2002) in resource partitioning.

\section{ACKNOWLEDGMENTS}

We thank James Nieh (University of California San Diego), Margaret Couvillon (University of Sussex), Cristiano Menezes (Embrapa Amazônia Oriental), and Gustavo Ruiz (Universidade Federal do Pará) for critical reading on the manuscript and linguistic advice, the staff of the Botany Laboratory of the Brazilian Enterprise for Agricultural Research (EMBRAPA/CPATU) for technical support during the experiments, the Prorectory for Research of the Federal University of Pará (PROPESP/UFPA) for the high-level publication program (PAPQ), and the National Council for Scientifical and Technological Development (CNPq) for the Masters scholarship granted to the first author (Proc. 556846/2009-5). 
Apprentissage de l'association temps-lieu chez l'abeille Melipona fasciculata (Apidae, Meliponini)

\section{Abeille sans aiguillon / collecte des ressources / activité d'anticipation / disponibilité de la ressource / apprentissage socio-temporel}

\section{Raum-zeitliches Lernen bei der Biene Melipona fasciculata (Apidae, Meliponini)}

\section{Stachellose Bienen / Sammeln von Resourcen / Futtererwartungsaktivität / Raum-zeitliches Lernen}

\section{REFERENCES}

Antle, M.C., Silver, R. (2009) Neural basis of timing and anticipatory behaviors. Eur. J. Neurosci. 30, 1643-1649

Bellusci, S., Marques, M.D. (2001) Circadian activity rhythm of the foragers of a eusocial bee (Scaptotrigona aff. depilis, Hymenoptera, Apidae, Meliponinae) outside the nest. Biol. Rhythm. Res. 32, 117-124

Beugnon, G., Pasturage-Ruiz, I., Schatz, B., Lachaud, J. (1996) Cognitive approach of spatial and temporal information processing in insects. Behav. Proc. 35, $55-62$

Biesmeijer, J.C., van Nieuwstadt, M.G.L., Lukács, S., Sommeijer, M.J. (1998) The role of internal and external information in foraging decisions of Melipona workers (Hymenoptera: Meliponinae). Behav. Ecol. Sociobiol. 42, 107-116

Biesmeijer, J.C., van Vries, H. (2001) Exploration and exploitation of food sources by social insect colonies: a revision of the scout-recruit concept. Behav. Ecol. Sociobiol. 49, 89-99

Breed, M.D., Stocker, E.M., Baumgartner, L.K., Vargas, S.A. (2002) Time-place learning and the ecology of recruitment in a stingless bee, Trigona amalthea (Hymenoptera, Apidae). Apidologie 33, 251-258

Camargo J.M.F., Pedro, S.R.M. (2012). Meliponini Lepeletier, 1836, In: Moure, J.S., Urban, D. \& Melo, G.A.R. (Orgs), Catalogue of Bees (Hymenoptera, Apoidea) in the Neotropical Region - online version. Available at http://www.moure.cria.org.br/catalogue. Accessed July/31/2013

Edge, A.A., Van Nest, B.N., Johnson, J.N., Miller, S.N., Naeger, N.L., Boyd, S.D., Moore, D. (2012) Diel nectar secretion rhythm in squash (Cucurbita pepo) and its relation with pollinator activity. Apidologie 43, $1-16$

Hubbell, S.P., Johnson, L.K. (1978) Comparative foraging behavior of six stingless bee species exploiting a standardized resource. Ecology 59, 1123-1136

Jammalamadaka, S.R., Sen Gupta, A. (2001) Topics in circular statistics. World Scientific Publishing Company, Singapore
Jarau, S., Hrncir, M., Schmidt, V.M., Zucchi, R., Barth, F.G. (2003) Effectiveness of recruitment behavior in stingless bees (Apidae, Meliponini). Insectes Soc. 50, 365-374

Johnson, L.K., Hubbell, S.P. (1974) Aggression and competition among stingless bees: field studies. Ecology 55, 120-127

Kerr, W.E., Petrere Jr., M., Diniz-Filho, J.A.F. (2001) Informações biológicas e estimativa do tamanho ideal da colméia para a abelha tiúba do Maranhão (Melipona compressipes fasciculata Smith-Hymenoptera, Apidae). Rev. Bras. Biol. 18, 45-52

Kronfeld-Schor, N., Dayan, T. (2003) Partitioning of time as an ecological resource. Annu. Rev. Ecol. Evol. System. 34, 153-181

Lichtenberg, E.M., Imperatriz-Fonseca, V.L., Nieh, J.C. (2010) Behavioral suites mediate group-level foraging dynamics in communities of tropical stingless bees. Insectes Soc. 57, 105-113

Michener, C.D. (2013) The Meliponini. In: Vit, P., Pedro, S.R.M., Roubik, D.W. (eds.) Pot-honey: a legacy of stingless bees, Springer Science+Business Media, pp. 3-17

Moore, D. (2001) Honey bee circadian clocks: behavioral control from individual workers to wholecolony rhythms. J. Insect Physiol. 47, 843-857

Moore, D., Van Nest, B.N., Seier, E. (2011) Diminishing returns: the influence of experience and environment on time-memory extinction in honey bee foragers. J. Comp. Physiol. A. 197, 641-651

Moore, D., Angel, J.E., Cheeseman, I.M., Fahrbach, S.E., Robinson, G.E. (1998) Timekeeping in the honey bee colony: integration of circadian rhythms and division of labor. Behav. Ecol. Sociobiol. 43, 147-160

Murphy, C.M., Breed, M.D. (2008) Time-place learning in a Neotropical stingless bee, Trigona fulviventris Guérin (Hymenoptera: Apidae). J. Kansas Entomol. Soc. 81, 73-76

Nagamitsu, T., Inoue, T. (1997) Aggressive foraging of social bees as a mechanism of floral resource partitioning in an Asian tropical rainforest. Oecologia 110, 432-439

Nieh, J.C. (2004) Recruitment communication in stingless bees (Hymenoptera, Apidae, Meliponini). Apidologie 35, 159-182

Nieh, J.C., Kruizinga, K., Barreto, L.S., Contrera, F.A.L., Imperatriz-Fonseca, V.L. (2005) Effect of group size on the aggression strategy of an extirpating stingless bee Trigona spinipes. Insectes Soc. 52, 1-8

Oda, G.A., Bellusci, S., Marques, M.D. (2007) Daily rhythms related to distinct social tasks inside an eusocial bee colony. Chronobiol. Int. 24, 845-858

Pahl, M., Zhu, H., Pix, W., Tautz, J., Zhang, S. (2007) Circadian timed episodic-like memory - a bee knows what to do when and also where. J. Exp. Biol. 210, 3559-3567

Peel, M.C., Finlayson, B.L., McMahon, T.A. (2007) Updated world map of the Köppen-Geiger climate classification. Hydrol. Earth Syst. Sci. 11, 1633-1644 
Saunders, D.S., Steel, C.G.H., Vafopoulou, X., Lewis, R.D. (2002) Insect clocks, 3rd edn. Elsevier Science B.V, Amsterdam

Schatz, B., Lachaud, J.P., Beugnon, G. (1999) Spatiotemporal learning by the ant Ectatomma ruidum. J. Exp. Biol. 202, 1897-1907

Schueller, T.I., Jeanne, R.L. (2012) Cue-mediated recruitment in a swarm-founding wasp: successful foragers induce nestmates to search off nest for a scented carbohydrate resource. Psyche . doi:10.1155/2012/585014

Slaa, E.J., Cevaal, A., Sommeijer, M.J. (1998) Floral constancy in Trigona stingless bees foraging on artificial flower patches: a comparative study. J. Apic. Res. 37, 191-198

Slaa, E.J., Tack, A.J.M., Sommeijer, M.J. (2003) The effect of intrinsic and extrinsic factors on flower constancy in stingless bees. Apidologie 34, 457-468

Teixeira, L.V., Waterhouse, J.M., Marques, M.D. (2011) Respiratory rhythms in stingless bee workers: circadian and ultradian components throughout adult development. J. Comp. Physiol. A. 197, $361-372$
Thorpe C.M., Wilkie D.M. (2006) Properties of timeplace learning, In: Wasserman E.A., Zentall T.R. (Org.). Comparative cognition: experimental explorations of animal intelligence, Oxford, Oxford University Press, U.S.A., pp. 229-245

Venturieri G.C., Alves D.A., Villas-Bôas J.K., Carvalho C.A.L., Menezes C., Vollet-Neto A., Contrera F.A.L., Cortopassi-Laurino M., Nogueira-Neto P., Imperatriz-Fonseca V.L. (2012) Meliponicultura no Brasil: situação atual e perspectivas futuras para o uso na polinização agrícola, In: Imperatriz-Fonseca V.L., Canhos D.A.L., Alves D.A., Saraiva A.M. (Orgs), Polinizadores no Brasil. EDUSP, São Paulo, pp. 213-236

von Frisch, K. (1993) The dance language and orientation of bees. Harvard University Press, Cambridge

Wagner, A.E., Van Nest, B.N., Hobbs, C.N., Moore, D. (2013) Persistence, reticence and the management of multiple time memories by forager honey bees. J. Exp. Biol. 216, 1131-1141

Zar, J.H. (1999) Biostatistical analysis. Prentice Hall, New Jersey 